\title{
BLOCKCHAIN E O FUTURO DOS CONTRATOS ADMINISTRATIVOS
}

\section{BLOCKCHAIN AND THE FUTURE OF ADMINISTRATIVE CONTRACTS}

\author{
Valter Shuenquener de Araujo ${ }^{1}$ \\ Marcia Gomes de Freitas ${ }^{2}$ \\ Maria Victoria Arantes Martin ${ }^{3}$
}

\section{RESUMO}

Nos últimos tempos, a literatura publicista tem se ocupado, dentre outros tópicos, do estudo dos reflexos causados por novas tecnologias no Direito Administrativo. Os efeitos de tais inovações impactam os mais variados aspectos das relações entre o Estado e o cidadão, impulsionando a releitura de clássicos institutos do direito. $\mathrm{O}$ presente artigo tem por propósito investigar em que medida a utilização da tecnologia blockchain, difundida a partir das relações que envolvem criptomoedas, pode ser adequada às licitações públicas e quais os impactos de sua aplicação na relação contratual da Administração Pública. A metodologia da pesquisa será bibliográfica e doutrinária e o objetivo do texto é o de contribuir para o debate do impacto das inovações tecnológicas no modo como os contratos administrativos são formalizados e executados.

Palavras-chave: Contratos administrativos. Novas tecnologias. Blockchain. Licitações. Inovações disruptivas.

\begin{abstract}
In recent times, the publicist literature is concerned, among other things, with the study of the impacts caused by new technologies in Administrative Law. The effects of such innovations extend to several aspects of the relations between the State and the citizen, impelling the review of classic law institutes. The purpose of this article is to investigate the extent to which the use of blockchain technology, disseminated through relationships involving crypto - currencies, may be appropriate to public biddings and what are the impacts of their application on the Public Administration contract relations. The research methodology will be bibliographic and doctrinal and the purpose of the text is to contribute to the debate on the impact of technological innovations in the way administrative contracts are formalized and executed.
\end{abstract}

\footnotetext{
${ }^{1}$ Faculdade de Direito da UERJ, Departamento de Direito do Estado, Mestre e Doutor em Direito Público pela UERJ e KZS pela Ruprecht-Karls Universität de Heidelberg. Faculdade de Direito da UERJ - Brasil. ORCID: https://orcid.org/0000-0003-1584-5340 Lattes: http://lattes.cnpq.br/8284713431239760 E-mail: vsaraujo19@gmail.com

${ }^{2}$ Mestre em Direito Público do Programa de Pós-Graduação em Direito da UERJ. Mestre em Direito Público pela UERJ. - Brasil. Lattes: http://lattes.cnpq.br/0219546531254896 E-mail: marciagfreitas@globo.com

3 Bacharel em Direito pela Universidade do Estado do Rio de Janeiro (UERJ). - Brasil. ORCID: https://orcid.org/0000-0003-1584-5340 Lattes: http://lattes.cnpq.br/8432065089162286 E-mail: mariavictoria.antunes@yahoo.com
} 
Keywords: Administrative contracts. New technologies. Blockchain. Bidding. Disruptive innovations.

\section{INTRODUÇÃO}

Os impactos causados pelo uso de novas tecnologias nas relações sociais têm ocupado a pauta de estudos nas mais variadas esferas do saber. Investiga-se, a título de ilustração, quais os reflexos que a exposição excessiva a jogos eletrônicos causa no desenvolvimento cognitivo de crianças e adolescentes, o que impõe sejam repensados os métodos pedagógicos tradicionais (GUNTER, 1998).

Como nunca antes, a tecnologia está transformando o modo de agir dos indivíduos e as relações interpessoais. Isso ocorre, por exemplo, através de aplicativos contidos nos smartphones, que permitem a comunicação facilitada, a solicitação de serviços e o pagamento online. A tecnologia, portanto, rompe a forma tradicional de se oferecer bens e serviços, possibilitando que eles sejam disponibilizados de modo mais eficiente, e tornando obsoletos os seus antecessores: é a chamada inovação disruptiva (CHRISTENSEN; RAYNOR, 2003). Assim, a partir de soluções relativamente simples, novos agentes econômicos ocupam um espaço no mercado que, até então, comportava apenas empresas já consolidadas.

No Direito, este fenômeno se faz cada vez mais presente e gera as mais variadas controvérsias jurídicas. Nesse contexto, o fornecimento de serviços com maior eficiência em virtude das novas tecnologias é um aspecto que precisa ser bem recepcionado e compreendido pelo ambiente jurídico e seus intérpretes.

Do mesmo modo, o Estado-administração, na condição de cliente expoente das relações contratuais firmadas em qualquer território, deve estar atento ao avanço dessas ferramentas de inovação, buscando adaptar seus métodos e sistemas, tais como os procedimentos licitatórios e a execução de contratos administrativos, a fim de extrair a sua máxima potencialidade (SILVA, 2011).

Este trabalho tem por propósito mais específico investigar em que medida a utilização da tecnologia blockchain, difundida a partir das relações que envolvem criptomoedas, pode ser adequada às licitações públicas e quais os impactos de sua aplicação nas relações contratuais da Administração Pública.

Para tanto, na primeira parte do texto abordaremos a simbiose inevitável que se opera entre o Direito Administrativo e as novas tecnologias. Comentaremos, ainda, como esse ramo 
das ciências jurídicas está reagindo ao avanço provocado pelas inovações tecnológicas disruptivas em três esferas de atuação estatal: i) o Estado-regulador; ii) o Estado-administração; e iii) o Estado como parte nas relações contratuais. Apresentaremos exemplos de espaços na Administração Pública que se tornaram amigáveis à implantação de sistemas inteligentes e que permitem um uso mais racional dos recursos públicos disponíveis.

$\mathrm{Na}$ segunda parte, analisaremos como as novas ferramentas tecnológicas poderão impactar o ambiente da contratação pública, tornando imperiosa a releitura dos institutos aplicáveis a esse nicho de atuação da Administração, de modo a adaptá-los às transformações impostas pela realidade.

À terceira parte ficou reservada a apresentação da ferramenta blockchain, mediante a síntese do seu histórico de surgimento e de como esse instrumento já é adotado em diversos ambientes de negócios, inclusive no Brasil.

Por fim, em uma abordagem prospectiva, demonstraremos como o blockchain, com todas as suas potencialidades, poderá impactar o futuro das contratações da Administração Pública, de maneira a tornar mais dinâmicos e racionais os procedimentos licitatórios e a gestão dos respectivos contratos administrativos.

\section{DIREITO ADMINISTRATIVO E NOVAS TECNOLOGIAS: UMA SIMBIOSE INEVITÁVEL}

A velocidade com que a inovação tecnológica opera mudanças nas relações jurídicas traz um grande desafio às instituições públicas e privadas, impondo verdadeiras revoluções em seus arranjos.

Embora tais reflexos sejam sentidos de forma mais contundente no passado recente através da multiplicação e disseminação, em escala global, das chamadas inovações disruptivas, esse fenômeno não representa exclusividade do nosso tempo. As inovações disruptivas já eram percebidas no limiar da década de 40 do século passado, ocasião em que, consoante destacado por Patrícia Baptista e Clara Keller, Joseph Schumpeter cunhou o conceito-chave "destruição criativa", verbis:

A despeito da grande velocidade com que as tecnologias vêm evoluindo e promovendo mudanças econômicas e sociais de grande impacto nos últimos anos, principalmente a partir das tecnologias digitais em rede, o desafio das instituições pela inovação não é exclusividade do nosso tempo. Percebendo essa realidade, em 1942, o economista Joseph Schumpeter publica pela primeira vez Capitalismo, 
socialismo e democracia, uma obra contundente sobre o desenvolvimento do sistema capitalista e seu futuro. Nela, Schumpeter apresenta aquele que se tornou um conceito-chave para o debate acerca dos desafios que a inovação tecnológica apresenta ao direito: a destruição criativa. Assim o autor identificou o processo característico dos sistemas econômicos capitalistas, pelo qual a estrutura econômica é constantemente revolucionada a partir dela mesma, destruindo antigas e criando novas lógicas econômicas (BAPTISTA; KELLER, 2016, p. 131).

No tocante aos desafios que essa conjuntura impõe ao Estado, é possível identificar e agrupá-los em três espécies, a depender da posição jurídica que este exerce em dado momento e circunstância. Assim, pode-se afirmar que as inovações exigirão atitudes e métodos de reação distintos, quando estivermos diante do i) Estado-regulador; ii) do Estado-Administração, e iii) do Estado na condição de parte nas relações contratuais.

\subsection{Inovação tecnológica e o Estado-regulador}

A revolução com que a inovação tecnológica atinge o Estado na qualidade de agente regulador das relações econômico-privadas se apresentou inicialmente como objeto de estudo no Direito Administrativo estrangeiro, ${ }^{4}$ mas encontrou forte eco na literatura publicista nacional. ${ }^{5}$

Em síntese, tais estudos concentram-se em responder três questões centrais a respeito da regulação de novas tecnologias: por quê, quando e como regulá-las?

A resposta à primeira questão, segundo Baptista e Keller, não foge às justificativas tradicionais para o exercício da atividade regulatória por parte do Estado. Por um lado, almejase a promoção de um amplo rol de direitos e garantias fundamentais, e, de outro, a correção das falhas de mercado, tais como as assimetrias de informações e as ameaças à livre concorrência. Contudo, prosseguem as autoras chamando atenção para o fato de que:

o debate sobre a legitimação da intervenção estatal em novas tecnologias não pode ser travado sem considerar-se a importância da promoção e preservação da

\footnotetext{
4 “The Social Control of Technology" (COLLINGRIDGE, 1980) é considerada uma obra pioneira no tema da regulação de novas tecnologias.

${ }^{5}$ Para uma abordagem da regulação de novas tecnologias na doutrina brasileira, v., dentre outros, GUERRA, Sérgio. Regulação estatal e novas tecnologias. Interesse Público - IP, Belo Horizonte, ano 18, n. 100, nov./dez. 2016; MARQUES NETO, Floriano de Azevedo; FREITAS, Rafael Véras de. Uber, WhatsApp, Netflix: os novos quadrantes da publicatio e da assimetria regulatória. Revista de Direito Público da Economia - RDPE, Belo Horizonte, ano 14, n. 56, out./dez. 2016; OLIVEIRA, Rafael Carvalho Rezende; FIGUEIROA, Caio Cesar. Desafios das reformas institucionais a partir de novas tecnologias: uma abordagem pragmática ao Direito Público a partir do caso Uber. Revista de Direito Público da Economia - RDPE, Belo Horizonte, ano 14, n. 54, abr./jun. 2016.
} 
inovação, como fator de produção essencial ao desenvolvimento econômico das sociedades (BAPTISTA; KELLER, 2016, p. 159).

Sob outro enfoque, a decisão a ser tomada sobre o momento mais apropriado para a regulação das novas tecnologias representa uma tarefa bem mais árdua do que a de justificar a atividade regulatória em si. Isto porque, dada a velocidade com que a chamada inovação disruptiva se apresenta, com reflexos imediatos nas relações jurídicas e sociais, o Estadoregulador se vê diante de um dilema quanto à postura correta a se adotar (TRUBNIKOV, 2017). Trata-se do "dilema de Collingridge" (Collingridge 485ilema), assim explicado por BENNETT MOSES:

Collingridge estava preocupado com o fato de como os reguladores poderiam responder a uma nova tecnologia, pois enfrentam dois obstáculos. No estágio inicial do desenvolvimento de uma tecnologia, a regulamentação era problemática devido à falta de informações sobre o provável impacto da tecnologia. Num estágio avançado, a regulamentação pode ser problemática porque a tecnologia fica mais popular, tornando dispendiosas as implementações exigidas pelos reguladores. O dilema decorre de estudos sociológicos da tecnologia, que sugerem que a 'flexibilidade interpretativa' é alta nos estágios iniciais do desenvolvimento de uma tecnologia, mas acaba se estabilizando de forma (mais ou menos) definitiva ("fechamento") após a estabilização." (BENNETT MOSES, 2013, p. 7). ${ }^{6}$

Exsurge a dúvida se é melhor agir de forma imprudente - regulando tecnologias sem a disponibilidade das informações mínimas necessárias -, ou ficar inerte frente ao avanço da inovação tecnológica (FENWICK; KAAL; VERMEULEN, 2017).

Ampliando a discussão sobre o Collingridge dilemma, Bennett Moses aponta que outra maneira para a compreensão deste mesmo fenômeno consiste em:

Reconhecer que os novos sistemas tecnológicos adquirem um 'impulso', à medida em que se tornam maiores e mais complexos, tornando-os mais resistentes ao estímulo regulatório. Isso sugere que os reguladores que desejam influenciar o design tecnológico (para evitar ou minimizar riscos de danos à saúde, ambientais e sociais, por exemplo) precisam agir em um estágio inicial, quando a situação é mais maleável. No estágio inicial, no entanto, pouco se sabe sobre as perspectivas da nova tecnologia, os danos que ela pode causar ou as formas que ela pode assumir.

Assim, os reguladores enfrentam um "paradoxo da incerteza", onde são forçados a tomar decisões na ausência de informações de risco confiáveis ou de

\footnotetext{
${ }^{6}$ No original: “Collingridge was concerned that regulators responding to a new technology faced twin hurdles. At an early stage in a technology's development, regulation was problematic due to the lack of information about the technology's likely impact. At a later stage, regulation was problematic as the technology would become more entrenched, making any changes demanded by regulators expensive to implement. The dilemma follows from sociological studies of technology that suggest that 'interpretive flexibility' is high in the early stages of a technology's development, but ultimately stabilises in a (more or less) final form ('closure') following stabilisation".
} 
conhecimento prévio dos desenvolvimentos tecnológicos. Até que ponto esses dois obstáculos se revelam como um dilema depende da rapidez e imprevisibilidade da mudança tecnológica, bem como do padrão de difusão associado à tecnologia em questão (BENNETT MOSES, 2013, p. 7-8).7

Portanto, não é fácil encontrar uma única resposta para a segunda questão acerca do melhor momento para a regulação, pois ela dependerá das circunstâncias e nuances de cada inovação tecnológica. O que se pode intuitivamente afirmar é que o Estado-regulador estará, geralmente, um passo atrás do fenômeno da inovação tecnológica.

O grande desafio atual é o de saber qual arranjo deverá ser adotado pelo Estado para a regulação das novas tecnologias. Como regular a nova tecnologia? E a resposta para essa questão, à semelhança do que ocorre em relação à escolha do momento mais oportuno para a regulação, também depende das características do fenômeno a ser regulado (SARMENTO, 2015). Verifica-se que, mesmo em casos de regulação de um mesmo fenômeno tecnológico, há a possibilidade de se conceber regulações diametralmente distintas, quando, por exemplo, a competência regulatória for atribuída a entes variados. Tal ocorreu na regulação dos serviços privados de transporte de passageiros da empresa Uber, em que se verificou uma miscelânea de arranjos regulatórios nos diversos municípios da Federação (BINENBOJM, 2017).

Um fator, no entanto, deverá ser observado, que consiste em reconhecer que a empreitada regulatória das novas tecnologias, embora perpasse de forma contundente pela esfera do Direito, contribuindo para o aprimoramento da ciência jurídica, também reclama uma atuação multidisciplinar do Estado, em função da complexidade que lhe é inerente. Neste sentido, Sergio Guerra aponta que:

o desenvolvimento e a sofisticação do conhecimento humano trazem uma especialização dos ramos jurídicos sem precedentes. Isso se revela na edição de legislações cada vez mais herméticas para a compreensão e operação das quais não bastam sólidos conhecimentos jurídicos, fazendo necessário a eles acoplar conhecimentos técnicos do setor específico normatizado. Tal especialização vai implicar não apenas uma segmentação dos instrumentos legais como vai construir diversos subsistemas (GUERRA, 2016, p. 205).

Guerra ressalta, também, que "para alcançar seus objetivos, a função de regulação deve perseguir o equilíbrio sistêmico dos setores regulados, e, para tanto, deve se valer de uma visão prospectiva, de modo a se afastar das decisões de momento e sem sustentabilidade". Nesse sentido, destaca a relevância atribuída às escolhas técnicas, em detrimento de escolhas políticas,

\footnotetext{
${ }^{7}$ Trecho em que se adotou tradução livre.
} 
reduzindo-se, assim, os juízos de conveniência e oportunidade típicos da discricionariedade. Isto porque, segundo o autor, "a função de regulação deve se caracterizar como sendo uma função de Estado e não de governo. Aquela preocupada com os efeitos sistêmicos e, portanto, prospectivos; esta preocupada com as urnas" (GUERRA, 2016, p. 205).

Vimos, portanto, que se opera uma simbiose entre a inovação tecnológica e o Direito Administrativo, tendo em vista que o surgimento de novas tecnologias está intimamente imbricado com as atribuições do Estado-regulador. Repisa-se que essa atribuição estatal não está amparada somente nos fundamentos clássicos da atividade regulatória - promoção dos direitos e das garantias fundamentais e correção das falhas de mercado -, mas tem como pressuposto a preservação da própria inovação tecnológica, pois ela representa um aspecto fundamental para o desenvolvimento social e econômico.

\subsection{Inovação Tecnológica e o Estado-Administração}

A exemplo do que ocorreu com os estudos sobre os impactos do avanço tecnológico na atividade regulatória estatal, os publicistas têm, de igual modo, se ocupado em compreender como tais impactos repercutem na atuação do Estado-Administração.

A Administração Pública figura como o elo principal entre o Estado e o cidadão no atendimento e promoção dos direitos fundamentais, atuando como a "casa de máquinas" do sistema jurídico-constitucional (GARGARELLA, 2013. pp. 172-195). Nessas circunstâncias, torna-se relevante o estudo de como as novas tecnologias poderão contribuir para o aprimoramento da atividade administrativa do Estado.

Do mesmo modo, tendo em vista a extensão da estrutura da Administração Pública brasileira, que decorre tanto da sua amplitude territorial, quanto da vasta gama de competências atribuídas ao Estado, as implicações que advêm da inovação tecnológica acabam por permear praticamente toda a atividade público-administrativa. E isso também justifica o esforço na identificação de soluções capazes de adaptar as diversas tarefas estatais à inovação tecnológica.

A promoção do primado da eficiência, alçado à condição de princípio basilar da Administração Pública pela Emenda Constitucional no 19/98, é outro aspecto que se une aos acima citados para justificar a necessidade de a Administração Pública lançar mão das potencialidades advindas da revolução operada pela tecnologia, a fim de fornecer ao cidadão um serviço público que conjugue a otimização dos recursos humanos e materiais com a qualidade desejada. 
Outro fator que impõe essa mudança de olhar da Administração Pública quanto à adoção de ferramentas tecnológicas consiste na crise da confiança nos governos, que se tornou uma realidade comum nos mais variados países ocidentais. A principal consequência de fatores como os escândalos de corrupção e a elevada carga tributária, que não retorna na quantidade e qualidade dos serviços prestados pelo Estado, é o descrédito generalizado nos governantes. Em virtude disso, a sociedade reivindica um governo que atue de forma mais transparente e ágil (MEDAUAR, 2003, p. 237; PIRES, 2016).

A despeito de existirem diversos fatores que nos levam a considerar como premente a abertura da Administração à inovação tecnológica, essa não é uma empreitada simples. E uma das principais razões a obstaculizar a mudança é a necessidade estatal da disponibilidade de vultosos recursos financeiros para concretizá-la, tanto na fase de implementação dessas ferramentas, quanto em momentos posteriores de treinamento de pessoal.

Por outro lado, vislumbra-se que a inovação tecnológica pode funcionar como um excelente antídoto à falta de recursos públicos. No mesmo sentido, Valter Shuenquener de Araújo ressalta que a "inovação tecnológica é o caminho mais seguro e inteligente para a superação das dificuldades. Por meio dela, os finitos recursos financeiros, públicos ou privados, não são desperdiçados e o Estado consegue atingir melhores resultados no desempenho das suas funções" (ARAUJO, 2018).

Acrescenta-se o fato de que a Administração Pública brasileira está tradicionalmente estruturada em um modelo, cuja forma de atuação caracteriza-se por ser mais lenta, haja vista que o processo decisório usualmente envolve uma extensa cadeia de agentes responsáveis por etapas distintas.

Apesar da constatação da existência de um grande aparato burocrático estatal, medidas têm sido tomadas para a implementação, no âmbito da Administração Pública, de um modelo de gestão mais conectado às tendências de inovação tecnológica, à semelhança do que tem sido experimentado no ambiente privado.

Em relação ao poder de polícia, por exemplo, a coercibilidade inerente a essa função estatal passa a ser questionada, tendo em vista que, consoante destacado por Valter Shuenquener de Araújo:

A prerrogativa da Administração de criar unilateralmente obrigações a serem adimplidas por particulares sofre abalos pela possibilidade de efetiva participação do cidadão no processo decisório de criação das manifestações do poder de polícia. Essa conclusão resulta especialmente da constatação de que as inovações tecnológicas nos 
revelam que o Estado não é a única fonte de regulamentação das liberdades individuais. Os cidadãos, usuários dos serviços disponibilizados por sistemas eletrônicos, participam da construção das regras aplicáveis e são seus destinatários. (ARAUJO, 2018, p. 1688) ${ }^{8}$

A discricionariedade, enquanto atributo do poder de polícia, também é impactada pelo crescente aumento da utilização de instrumentos de inteligência artificial para a formação da decisão estatal, o que impõe um estreitamento maior do espaço de escolha do administrador público. A clássica avaliação de conveniência e oportunidade tende a ser superada por parâmetros objetivos extraídos dos códigos desses novos sistemas.

Em relação à atuação dos órgãos de controle, como é o caso do Tribunal de Contas, o uso das novas tecnologias pode propiciar uma maior racionalidade no controle de gastos.

É perceptível, portanto, que novas tecnologias estão impactando e transformando as categorias do Direito Administrativo, e podem revolucionar na otimização do emprego dos recursos disponíveis, a fim de garantir que o Estado-Administração exerça seu papel de gestão do patrimônio e do interesse públicos de forma mais dinâmica e eficiente.

\subsection{Inovação tecnológica e o Estado enquanto agente das relações econômicas}

As inovações tecnológicas atingem de forma mais contundente, ao menos em um primeiro momento, as relações privadas, sobretudo aquelas afetas a contextos econômicos de contratação de bens e serviços. A tecnologia rompe a forma tradicional de se oferecer bens e serviços, possibilitando que eles sejam disponibilizados de modo mais eficiente e tornando obsoletos os seus antecessores. Assim, a partir de soluções relativamente simples, novos participantes têm ocupado um espaço no mercado que, até então, comportava apenas empresas já consolidadas. Apesar da preponderância dos efeitos desse fenômeno nas relações privadas, as instituições estatais também estão inseridas na necessidade de mudança. É que o Estado, além de desempenhar um papel relevante como agente regulador da atuação privada, também figura como sujeito contratante de bens e serviços.

\footnotetext{
${ }^{8}$ Valter Shuenquener de Araújo destaca três esferas do Direito Administrativo que já é possível constatar mudanças operadas por novas tecnologias, bem como projeções futuras decorrentes do impacto dessa inovação em tais categorias jurídicas. São elas i) o poder de polícia; ii) o regime jurídico dos servidores públicos; e iii) o controle administrativo. (ARAUJO, 2018, p. 1688).
} 
Dados extraídos do Painel de Compras do Governo Federal apontam que, apenas no primeiro semestre de 2019, foram contabilizados 15.612 processos de compras nos diversos órgãos da União. Esses processos representam um gasto da ordem de R \$ 4.125.580.307,68. No ano de 2018, foi registrado o total de 102.678 processos de compra, perfazendo o valor de $\mathrm{R} \$$ 47.785.226.845,40. ${ }^{9}$

Esses dados, que representam meramente uma parcela do total de contratos celebrados pelo Estado, porque não compreendem os números alusivos aos estados e municípios, revelam a importância da Administração Pública enquanto agente econômico.

Atualmente, percebe-se uma salutar transformação no Direito Administrativo quanto aos direitos da Administração e do particular nos contratos administrativos. Em contextos em que o Estado celebra um contrato com um particular, ele deve despir-se de seu poder de império e atuar pautado por uma relação genuinamente paritária. Nesse sentido, os dogmas inseridos no regime das contratações públicas, como a presença das chamadas cláusulas exorbitantes, não subsistiriam a uma leitura moderna do Direito Administrativo. As referidas cláusulas, que, na realidade, são prerrogativas previstas em lei em favor da Administração Pública, mais prejudicam o interesse público, a sociedade e o Estado do que ajudam. Poder, por exemplo, tornar-se inadimplente por até noventa dias é previsão legal que estimula a irresponsabilidade na gestão, a falta de planejamento orçamentário e que obriga o licitante a apresentar uma proposta com valores mais elevados.

Sobre o tema, Di Pietro leciona que os ventos dessa nova lógica atribuída ao Direito Administrativo, e que afetam o regime jurídico dos contratos administrativos, já podem ser sentidos com bastante força no contexto europeu. Em suas palavras:

Dentre as inovações, no âmbito da União Europeia, cabe mencionar, dentre outras, a substituição do conceito de serviço público por serviço econômico de interesse geral, o abrandamento ou extinção de algumas das cláusulas exorbitantes dos contratos administrativos, a força crescente das fontes internacionais do direito (já que os Tratados têm força normativa superior à da legislação interna, inclusive à própria Constituição). Também no direito europeu se fala do crescimento do direito público econômico ou direito administrativo econômico. Esse crescimento, segundo Jacqueline Morand-Deviller, representa significativamente "uma vontade de aproximação aos modos de gestão do Direito Privado e ao pragmatismo do Direito anglo-saxão". (DI PIETRO, 2016, p.185).

\footnotetext{
${ }^{9}$ Disponível em http://paineldecompras.planejamento.gov.br. Acesso em: 30/06/2019.
} 
Ressalta-se, contudo, que, no caso brasileiro, essa fuga para o direito privado é realizada com maior parcimônia, tendo em vista a presença de normas, sobretudo aquelas de estatura constitucional, que impedem que a Administração Pública se afaste por completo do regime de direito público, havendo, em certos casos, um movimento em sentido inverso, em uma clara tendência plublicizadora. Nesse sentido, Di Pietro sintetiza:

\begin{abstract}
A fuga para o direito privado que ocorre no direito brasileiro assemelha-se à que ocorre no âmbito da União Europeia no que diz respeito à intenção, que é a de fugir às "amarras" do regime jurídico administrativo; mas afasta-se daquele modelo quando defende que a utilização do direito privado libera a Administração Pública das prerrogativas e sujeições próprias do regime jurídico administrativo. O próprio direito positivo, inclusive a Constituição, contém normas que se aplicam independentemente de ser de direito público ou de direito privado o instituto utilizado; é o caso dos princípios referidos no artigo 37 da Constituição, da exigência de licitação, das cláusulas exorbitantes dos contratos administrativos (aplicadas, em grande parte, aos contratos de direito privado). Existe, no direito brasileiro, forte tendência à publicização dos institutos de direito privado utilizados pela Administração Pública. Basta verificar as normas da Lei $\mathrm{n}^{\circ}$ 13.303/2016, que estabeleceu o estatuto jurídico das empresas estatais; e a Lei ${ }^{\circ}$ 13.019/2014, sobre parcerias com o terceiro setor: em ambas é muito grande a derrogação do direito privado, embora essas leis tratem de pessoas jurídicas de direito privado. Também na jurisprudência há tendência publicizadora, especialmente com relação às entidades da administração indireta (fundações públicas e empresas estatais) (DI PIETRO, 2016, p.185).
\end{abstract}

Nessa conjuntura, a incorporação de novas tecnologias pelo Estado no ambiente da contratação pública se justifica não apenas em virtude da aproximação entre os regimes jurídicos, mas, também, pelo fato de os agentes econômicos privados, com as quais o Estado mantém relação contratual, investirem em ferramentas tecnológicas para a ampliação dos seus ganhos. Tais instrumentos podem reduzir e otimizar os custos de produção e, consequentemente, elevar a margem de lucro sobre os bens e serviços.

Outra faceta dessa onda de transformações e que justifica a releitura da atuação do Estado nas relações econômicas é a necessidade de a Administração Pública ter uma atuação mais pragmática. Ter um modo de proceder focado na realidade subjacente e sem desconsiderar as consequências das escolhas do agente público. ${ }^{10}$

De fato, verificou-se o surgimento de algumas iniciativas do legislador na área de contratações públicas. Foram editadas normas que contribuem para dinamizar o processo de

\footnotetext{
${ }^{10}$ Gustavo Binenbojm, na obra que revisitou o instituto do poder de polícia, identifica as duas facetas do fenômeno de transformação do direito administrativo, para as quais deu os nomes de "giro democrático-constitucional" e "giro pragmático". BINENBOJM, Gustavo. Poder de polícia, ordenação e regulação: transformações políticojurídicas, econômicas e institucionais do Direito Administrativo Ordenador. Belo Horizonte: Fórum, 2017.
} 
aquisição de bens e prestação de serviços, valendo-se do uso de ferramentas tecnológicas. São exemplos a Lei n ${ }^{0}$ 10.520/2002 (Lei do Pregão) e o Decreto no 5.450/2005 (Pregão Eletrônico). A Administração Pública Federal tem adotado, de forma expressiva, o pregão eletrônico para a contratação de seus bens e serviços. Segundo dados do Painel Processos de Compras, extraídos do primeiro semestre de 2019 , o pregão representou cerca de $22 \%$ dos processos licitatórios (3.435 processos), sendo que destes, quase a totalidade $(99,85 \%)$ ocorreu na forma eletrônica. ${ }^{11}$

A disponibilização de dados através do referido painel é um exemplo importante de como a tecnologia pode ser adotada para a otimização do gasto público e o reforço da transparência, medida esta salutar para o controle social da regularidade das contratações. Porém, há lacunas no sistema de contratação pública que, ainda, necessitam ser exploradas e revisitadas sob a ótica da inovação, tema que será abordado no tópico a seguir.

\section{IMPACTOS TECNOLÓGICOS NA CONTRATAÇÃO PÚBLICA}

A despeito da crescente utilização do pregão eletrônico - que representa, conforme acima destacado, cerca de $22 \%$ dos processos de compras da União -, a maior parte das licitações promovidas pela Administração Pública Federal e dos processos de contratação direta por dispensa e inexigibilidade se sujeita à disciplina da Lei $n^{o}$ 8.666/93. Esta lei, em que pese ter sido objeto de alterações pontuais, reflete uma estrutura que precede às transformações operadas no Direito Administrativo, dentre elas os influxos da inovação tecnológica.

A Lei $n^{0} 8.666$, que deveria se limitar a traçar parâmetros mínimos e gerais, cria regras procedimentais bem detalhadas, desconsiderando a realidade das repartições públicas, muitas dessas carentes de recursos humanos e materiais, para exercerem com eficiência suas funções. Do mesmo modo, o estabelecimento exaustivo de regras procedimentais pela via legislativa enseja o engessamento burocrático da atuação administrativa induz a ineficiência nas contratações, bem como acarreta o empoderamento desmedido dos órgãos de controle, dificultando a incorporação de inovações tecnológicas. $\mathrm{O}$ administrador se encontra, assim, tolhido de adotar uma gestão negocial mais criativa, que invista em soluções pragmáticas, a exemplo daquelas vivenciadas no ambiente corporativo. Na lógica da produção normativa,

\footnotetext{
${ }^{11}$ Disponível em http://paineldecompras.planejamento.gov.br. Acesso em: 30/06/2019.
} 
ainda há uma premissa errônea de que quanto maior for a burocracia e mais detalhado e rigoroso for o procedimento licitatório, menor será o risco de práticas desonestas em um certame.

Muito embora exista uma preocupação do legislador federal com a mudança do regime previsto na Lei $n^{\circ} 8.666 / 93$, a consulta aos projetos de lei em tramitação no Congresso Nacional, em especial ao PL no 1.292/95 aprovado pelo Plenário da Câmara dos Deputados em setembro de 2019, nos permite concluir que não houve uma preocupação em avançar nas questões referentes à adoção de sistemas tecnológicos inteligentes. ${ }^{12}$ Portanto, por melhores que tenham sido as intenções na implementação de mudanças significativas nas contratações públicas, a demora na tramitação já torna o texto aprovado desatualizado, notadamente no que diz respeito às soluções tecnológicas que poderiam ter sido consideradas no âmbito das licitações e contratações.

Por outro lado, não se pode exigir do legislador uma atuação exaustiva nas questões alusivas à inovação tecnológica. De fato, nesta seara, conforme tratamos no tópico anterior, o Estado-regulador fica diante do Collingridge dilemma. Sobre este ponto, cabe uma indagação: o dilema se o Estado-regulador deverá regular tecnologias sem a posse de todas as informações necessárias, ou se deverá manter-se inerte diante da inovação tecnológica (FENWICK; KAAL; VERMEULEN, 2017), se impõe, de igual modo, ao Estado-Administração?

A resposta a esse questionamento é positiva. Tanto no caso em que o Estado atua na organização dos seus serviços internos (Estado-administração), quanto nas hipóteses em que contrata com particulares, ele estará diante da escolha apontada por David Collingridge.

Contudo, pode-se afirmar que nesses, dois casos, há um delay ainda maior frente à inovação tecnológica. Isso porque, ao menos no Brasil, o estabelecimento de regras procedimentais em matéria de licitações e contratos é matéria reservada à lei. Essa, por seu turno, costuma ser exaustivamente detalhada, excluindo espaços de liberdade para a atuação do gestor. Essa forma de legislar acaba dificultando, portanto, que o administrador público opte por soluções proporcionadas por inovações tecnológicas em matéria de licitações e contratos.

Assim, uma nova questão se apresenta, qual seja: a dinâmica estabelecida nas relações negociais, em que se verifica a adoção de ferramentas tecnológicas nas transações econômicas

\footnotetext{
12 O Projeto de Lei $n^{\circ}$ 1.292/95, aprovado pela Câmara dos Deputados em 17/09/2019 e remetido ao Senado Federal em 10/10/2019, pretende alterar substancialmente o regime jurídico das licitações e contratos. Disponível em: https://www.camara.leg.br/propostas-legislativas/16526. Acesso em: 13/02/2020.
} 
privadas, pode ser incorporada à contratação pública brasileira, sem que, para tanto, seja necessária a intervenção do legislador?

Nesse aspecto, compreendemos que a atuação eficiente e o protagonismo do Estado nas relações jurídicas contratuais são importantes fatores que justificam uma maior liberdade ao gestor público para buscar as melhores soluções tecnológicas para a contração. Como consequência, há um ganho em termos de eficiência na gestão, e o Estado terá relações contratuais de forma mais dinâmica e racional.

\section{A TECNOLOGIA BLOCKCHAIN}

Em termos técnicos, blockchain é uma estrutura de dados que trafega numa rede peerto-peer ${ }^{13}$. Esta rede, por sua vez, consiste numa arquitetura de redes de computadores em que cada ponto participante funciona simultaneamente como cliente e servidor e ela é utilizada para armazenar e compartilhar dados imutáveis ${ }^{14}$.

O conceito de blockchain surgiu junto com o whitepaper da moeda virtual Bitcoin ${ }^{15}$, escrito por Satoshi Nakamoto e significa, em sua tradução para o português, blocos encadeados. Cada bloco reúne um conjunto de informações e possui uma identificação única (denominada de hash criptográfico ${ }^{16}$ ), que é utilizada obrigatoriamente no início do bloco subsequente. Vale dizer, o próximo bloco guarda a unicidade do bloco anterior, e, assim, sucessivamente, formando identificadores únicos que mapeiam a cadeia de informações.

O hash criptográfico, portanto, funciona como uma espécie de chave, portando dados de entrada do bloco anterior e criando dados de saída para utilização no bloco subsequente. $\mathrm{O}$ protocolo da criptomoeda Bitcoin, por exemplo, utiliza a função hash para transformar um grande número de informações em uma sequência numérica hexadecimal de tamanho fixo ${ }^{17}$.

13 LUCENA, A. U., Estudo de arquiteturas dos blockchains de Bitcoin e Ethereum. Disponível em: https://www.fee.unicamp.br/sites/default/files/departamentos/dca/eadca/eadcaix/artigos/lucena_henriques.pdf. Acesso em: 20/06/2020.

14 LUCENA, A. U., Estudo de arquiteturas dos blockchains de Bitcoin e Ethereum. Disponível em: https://www.fee.unicamp.br/sites/default/files/departamentos/dca/eadca/eadcaix/artigos/lucena_henriques.pdf. Acesso em: 20/06/2020.

${ }^{15}$ NAKAMOTO, Satoshi. Bitcoin: A Peer-to-Peer Electronic Cash System. Disponível em https://bitcoin.org/bitcoin.pdf. Acesso em: 20/02/2020.

16 WANG, Dexi; JIANG, Yu; SONG, Houbing, et al Verification of Implementations of Cryptographic Hash Functions. Disponível em: https://ieeexplore.ieee.org/abstract/document/7924403. Acesso em: 20/06/2020.

17 MACEDO, R. T., Pataca: um sistema de promoção da descentralização da moeda através de moedas criptográficas. 2014. Trabalho de formatura (Bacharelado) - Instituto de Matemática e Estatística, Universidade 
Assim, uma sequência de caracteres de entrada cria uma sequência de dezesseis letras e números aleatórios de saída que serão utilizados para fins de verificação na entrada do bloco seguinte.

Outra importante tecnologia usada pelo blockchain é a Tecnologia de Registros Distribuídos (Distributed Ledger Technology), isto é, o armazenamento dos dados no livro razão é descentralizado e distribuído através de cópias entre todos os participantes ${ }^{18}$. O tráfego dos dados através de uma rede peer-to-peer garante a imutabilidade das informações e, pelo fato de ser um sistema em que todos podem criar novos registros e, ao mesmo tempo, acessar as mesmas informações, proporciona-se alta confiabilidade aos usuários da rede.

Assim, se uma alteração for feita em um dado em alguma das cópias ao longo desses blocos, a verificação do hash criptográfico não permitirá que haja a validação desses blocos e a cópia alterada será desconsiderada por não ser fidedigna, ou seja, a alteração realizada em um dado não obterá o consenso da rede. Desse modo, a tecnologia blockchain assegura que o dado não seja alterado, possibilitando que o usuário não precise depositar a confiança em uma única entidade central. Em virtude desse armazenamento descentralizado dos dados, a tecnologia também proporciona segurança contra o ataque de hackers e máquinas infectadas, uma vez que, se um dos participantes estiver vulnerável a esses ataques, as cópias dos dados estarão seguras, em virtude da validação realizada pelas demais máquinas.

No caso da criptomoeda Bitcoin, os mineradores têm a função de validar as transações e encaixá-las nos blocos, encontrando a sequência de identificação única do bloco (hash) e tornando o bloco de transações da criptomoeda compatível com o bloco anterior ${ }^{19}$. Esse processo, conhecido por mineração, é realizado através de máquinas especializadas que, após milhares de cálculos por segundo, identificam a combinação certa de caracteres que foi utilizada. Dessa forma, sempre que uma transação na rede Bitcoin for realizada, o registro básico desta operação será feito no livro razão utilizando o sistema blockchain, contendo a função hash para garantir a inviolabilidade dos dados ${ }^{20}$. Estima-se que a cada dez minutos um

\footnotetext{
de São Paulo, São Paulo, 2014. [Orientador: Prof. Dr. Flávio Soares; Coorientador: Prof. Dr. Gilson Schwartz]. Disponível em: https://bcc.ime.usp.br/tccs/2014/rickmacedo/monografia.pdf. Acesso em: 20/06/2020.

${ }^{18}$ BELMIRO, N. João, Blockchain e o Potencial de Novos Modelos de Negócios: Um Mapeamento Sistemático. Disponível em: https://search.proquest.com/openview/3e86da5605e6dbdce8bc84dad8fd8ecb/ Acesso em: 20/06/2020.

19 RODRIGUES, E. I., Estudo sobre Bitcoin: escalabilidade da blockchain. Disponível em: http://www.elias19r.com/files/cv/tcc1-monografia_7987251.pdf?i=1. Acesso em 20/06/2020.

20 NAKAMOTO, Satoshi. Bitcoin: A Peer-to-Peer Electronic Cash System. Disponível em: https://bitcoin.org/bitcoin.pdf. Acesso em: 20/06/2020.
} 
novo bloco de transações é formado no Bitcoin, justificando-se, em virtude disso, o papel altamente importante dos mineradores nas transações da rede. Como recompensa por essa atividade, o minerador recebe uma quantia de Bitcoin, determinada pelo protocolo, por cada bloco minerado ${ }^{21}$.

Até o ano de 2012, havia somente uma rede blockchain, que é utilizada, até hoje, pelo Bitcoin. Com o passar dos anos e o desenvolvimento dessa tecnologia, surgiram outras redes blockchain com características diferentes, de modo a atender à necessidade específica de cada demanda. Atualmente, algumas plataformas se apresentam no plano público ou descentralizado, como a do Bitcoin, outras, por sua vez, se apresentam no plano privado ${ }^{22}$ e permitem que, apenas, usuários selecionados participem dessa rede, que é permissionada. Ressalta-se que, na rede blockchain pública, a segurança é garantida a partir de algoritmos de consenso, em que os próprios participantes são responsáveis pela segurança, pela escrita e pela validação dos dados presentes.

A transparência do blockchain é proporcionada pelo alto grau de rastreabilidade de cada transação, devido às transações serem sempre registradas no livro-razão, que apresenta a origem e destino de cada uma delas ${ }^{23}$. As transações podem ser rastreadas nas redes públicas através de chaves criptográficas públicas anônimas geradas por cada usuário, conhecida por endereço. Enquanto nas redes privadas a segurança é garantida pela aprovação prévia de participantes selecionados e a identidade desses participantes é conhecida.

A título de exemplo, no Brasil, o Banco Nacional de Desenvolvimento Econômico e Social (BNDES) criou um programa piloto denominado "BNDESToken" que utiliza a rede Ethereum $^{24}$ e que tem por objetivo rastrear a aplicação de recursos públicos em operações de crédito com entes públicos ou operações com recursos não reembolsáveis ${ }^{25}$. O programa

21 RODRIGUES, E. I., Estudo sobre Bitcoin: escalabilidade da blockchain. Disponível em: http://www.elias19r.com/files/cv/tcc1-monografia_7987251.pdf?i=1. Acesso em 20/06/2020.

22 GREVE, Fabíola; SAMPAIO, Leobino; ABIJAUDE, Jauberth; et al, Blockchain e a Revolução do Consenso Sob Demanda. Disponível em: http://143.54.25.88/index.php/sbrcminicursos/article/view/1770/1743. Acesso em: $20 / 06 / 2020$

${ }^{23}$ GOMES, V. J. F.; UCHOA, F. B. B.; SANTOS, T. F. S. Mapeamento Tecnológico das Patentes Desenvolvidas a partir da Tecnologia Blockchain: um cenário global. Disponível em: https://portalseer.ufba.br/index.php/nit/article/view/27193/MAPEAMENTO\%20TECNOL\%C3\%93GICO\%20D AS\%20PATENTES\%20DESENVOLVIDAS\%20A\%20PARTIR\%20DA\%20TECNOLOGIA\%20BLOCKCHA IN\%3A\%20UM\%20CEN\%C3\%81RIO\%20GLOBAL. Acesso em: 20/06/2020.

24 BUTERIN, Vitalik, A next generation smart contract \& decentralized application platform. Disponível em: https://cryptorating.eu/whitepapers/Ethereum/Ethereum_white_paper.pdf. Acesso em: 22/06/2020.

25 Disponível em https://www.bndes.gov.br/wps/portal/site/home/imprensa/noticias/conteudo/bndes-lancaconsulta-publica-em-busca-de-componentes-blockchain-para-o-bndestoken. Acesso em: 30/06/2019. 
funciona da seguinte forma: cada unidade do BNDESToken atua como uma representação digital da moeda brasileira, no valor de um real, liberado pelo BNDES às pessoas jurídicas beneficiadas. É possível que essas pessoas jurídicas realizem aquisições de produtos e serviços e efetivem o pagamento de fornecedores a partir do BNDESToken, e estes poderão, por sua vez, resgatar posteriormente o token convertido em real junto ao BNDES. Importa ressaltar que, para que o fornecedor da entidade beneficiada receba o BNDESToken, é necessário que seja feito previamente um cadastro na plataforma utilizada, com o número do Cadastro Nacional de Pessoas Jurídicas. Desta forma, o referido banco também pode rastrear pelo CNPJ e pelo BNDESToken as empresas que recebem algum tipo de aporte de capital através das diversas linhas de crédito da instituição, podendo ser verificado, consequentemente, se a entidade realmente está cumprindo os termos do contrato firmado no momento do dispêndio do capital.

Por fim, no âmbito internacional, a tecnologia blockchain já é utilizada em muitos dos registros de dados dos estados. A Estônia, por exemplo, implantou o sistema denominado "eEstonia", que conecta os sistemas nacionais de justiça, saúde, segurança, legislativo e comercial, armazenando-os de forma segura em relação à corrupção e uso indevido. No processo legislativo, o país utiliza o sistema e-Law, formalmente conhecido por Eletronic Coordination System for Draft Legislation (Sistema de Coordenação Eletrônica para Projetos de Legislação) que, através da rede de blockchain, possibilita ao público o acesso a informações referentes a projetos de lei enviados desde 2003, podendo ser consultado pela sociedade o autor da legislação, bem como o status atual e alterações feitas ao longo do processo parlamentar. ${ }^{26}$

\section{BLOCKCHAIN E O FUTURO DOS CONTRATOS ADMINISTRATIVOS}

A segurança oferecida pelo blockchain pode contribuir para a contratação pública em diversos pontos. Diante da desnecessidade de se depositar a confiança em uma única entidade central, é possível tornar o processo de contratação pública dificilmente corruptível e, consequentemente, mais confiável. No que tange especificamente à licitação, a utilização da tecnologia blockchain é viável, ao menos, nas fases de habilitação e julgamento das propostas. A partir do momento em que o contrato entre o ente público e o particular é firmado, é possível que a rede blockchain seja utilizada, de modo a tornar os contratos inteligentes e

${ }^{26}$ Disponível em www.e-estonia.com/solutions/security-and-safety/e-law/ Acesso em: 20/02/2020. 
autoexecutáveis ${ }^{27}$.

Como é cediço, a Lei $n^{\circ}$ 8.666/93 dispõe que o licitante precisa, antes de encaminhar a sua proposta, habilitar-se no processo licitatório. Nesta fase, a rede blockchain impactará de forma positiva o modus operandi da Administração Pública em grande parte das modalidades de licitação.

Esse é o primeiro ponto possível de ser simplificado, uma vez que grande parte dos documentos solicitados pelos órgãos públicos às empresas participantes nesta fase são emitidos por órgãos governamentais. Assim, os dados solicitados pelos órgãos podem ser disponibilizados através do blockchain pela própria Administração, garantindo a veracidade das informações ali contidas, de forma acessível e rápida.

Atualmente, nesta fase, os participantes podem impugnar a habilitação dos concorrentes que apresentarem documentos suspeitos ou insuficientes, o que, muitas vezes, retarda o processo. Nesta fase de habilitação, a ferramenta permitirá a redução do número de impugnações, tendo em vista a garantia de veracidade das informações disponibilizadas.

Assim, na medida em que a fase burocrática de habilitação das empresas na licitação for simplificada a partir do uso da tecnologia aqui sugerida, o processo de licitação terá sua duração encurtada e garantirá a autenticidade de todos os documentos, já que eles poderão ser inseridos na plataforma pelos órgãos e entidades responsáveis pela sua emissão.

Para que isso seja possível, é necessário, primeiro, que haja uma rede blockchain a ser utilizada pela Administração Pública e, segundo, que os órgãos responsáveis pela emissão dos documentos necessários à fase de habilitação das empresas no processo licitatório tenham um cadastro permissionado na rede utilizada, de modo que possibilite a inserção dessas informações. É possível, ainda, que as informações fornecidas na rede estejam disponíveis para que a empresa participante possa acompanhar a documentação e verificar os dados ali contidos.

Uma inovação que também tem potencial de proporcionar maior lisura nos contratos firmados pelo poder público são os denominados smart contracts, ou contratos inteligentes, que integram normas de procedimentos a partir da tecnologia blockchain e, consequentemente, conferem o caráter de confiabilidade proporcionado por essa rede pelos motivos expostos anteriormente. Os smart contracts são autoexecutáveis, pois possuem comandos a serem aplicados em um fluxograma com possibilidades previstas. Dessa forma, é possível que, por

27 SZABO, Nick, Formalizing and Securing Relationships on Public Networks, Disponível em: https://journals.uic.edu/ojs/index.php/fm/article/view/548/469 Acesso em: 22/06/2020. 
exemplo, o contrato tenha a previsão de que, na hipótese de alguma cláusula eventualmente ser descumprida pelo contratado, uma multa seja automaticamente aplicada em virtude dessa inadimplência.

A partir da utilização dos smart contracts pela Administração Pública, determinado contrato pode ser disponibilizado em uma plataforma colaborativa a ser acessada pela equipe responsável pela realização das etapas de verificação orçamentária e justificativas que a motivaram. Assim, o estudo técnico preliminar passaria a ser um processo e o seu produto final seria um termo de referência, que, posteriormente, seria transformado em uma espécie de algoritmo-Edital e disponibilizado ao público no portal de compras. A partir disso, os potenciais licitantes também podem ter a possibilidade de selecionar filtros em seus navegadores para que sejam notificados sobre licitações abertas. Superada a fase de habilitação, que, também, pode ser realizada a partir do blockchain, conforme exposto, o contrato pode ser assinado digitalmente pelo licitante. Na fase de execução, por sua vez, os procedimentos podem ser documentados pelos fornecedores e rastreados no livro-razão de forma similar ao BNDESToken e, dessa forma, é possível verificar se os termos do contrato estão sendo executados corretamente pelo contratado. Assim, na hipótese de alguma cláusula contratual ter sido desrespeitada sem que tenha sido apresentada e registrada uma justificativa razoável, é possível programar um comportamento autoexecutável que seja adotado pela Administração Pública, gerando, com a necessária observância do contraditório, advertências, cobranças e, até mesmo, multas e suspensões.

A fase de julgamento das propostas nas licitações públicas poderia ser simplificada a partir do uso de uma rede blockchain, de modo que a seleção dessas propostas possa ser realizada a partir do momento em que a empresa fornece à plataforma o atendimento dos critérios de seleção e demonstre a possibilidade de atender à determinada demanda da Administração Pública. É possível a utilização do blockchain tanto para a verificação pela sociedade de que a melhor proposta está realmente sendo escolhida, como, também, para viabilizar a utilização de comandos autoexecutáveis que selecionem automaticamente a melhor proposta e que, consequentemente, impeçam fraudes nesta fase. Dessa forma, a tecnologia oferecida pelo blockchain pode proporcionar uma otimização das licitações e contratações públicas, inclusive em relação à fase de execução do contrato, de modo a simplificar todo o processo. 


\section{CONSIDERAÇÕES FINAIS}

O presente artigo teve por propósito demonstrar que a Administração Pública deve, sempre que houver benefícios, incorporar as inovações tecnológicas em suas licitações e contratações e utilizar a ferramenta blockchain, que é difundida a partir das relações jurídicas que envolvem criptomoedas, a fim de adequá-la às suas necessidades.

O estudo da adoção de uma inovação tecnológica pela Administração Pública constitui parte relevante do processo de releitura dos institutos do Direito Administrativo, que se desenvolve tanto no Brasil quanto em outros países. Assim, é possível concluir que o Direito Administrativo e a Inovação Tecnológica mantêm uma verdadeira relação simbiótica no processo de transformação desse ramo do Direito.

A simbiose com a inovação se manifesta basicamente em três circunstâncias distintas, a depender da forma de atuação do Estado frente à inovação. Nesse contexto, o Estado pode agir como regulador das novas tecnologias, pode aplicá-las no âmbito dos seus serviços, ou mesmo usufruir dos seus benefícios para otimizar a gestão dos processos licitatórios e contratos.

Verificamos, de igual modo, que há muito a ser explorado em relação à inovação na Administração Pública, em especial no campo da disciplina contratual, pois o arranjo normativo nessa seara, que, ainda, é marcado pelo estabelecimento exaustivo de regras procedimentais pelo legislador, acaba por inibir a atuação mais criativa do administrador público na busca de soluções.

Nesse sentido, o blockchain, por ter como características principais a confiabilidade e integridade no trato das informações, pode ser adotado em várias fases do procedimento licitatório, como na habilitação e escolha do licitante vencedor, reduzindo, assim, eventuais falhas nesses procedimentos. De igual modo, a Administração Pública poderá se valer dessa tecnologia na implantação de smart contracts (contratos inteligentes), impulsionando verdadeira revolução na sistemática atualmente vigente, conferindo maior economia, eficiência e racionalidade à gestão do patrimônio público.

\section{REFERÊNCIAS}

ARAUJO, Valter Shuenquener de. Efeitos da inovação no Direito Administrativo brasileiro: queremos saber o que vão fazer com as novas invenções. Revista Quaestio Juris. Vol. 11, $\mathrm{n}^{\circ}$ 03, pp. 1687-1703, Rio de Janeiro, 2018. DOI: 10.12957/rqi.2018.32568. 
BAPTISTA, Patrícia; KELLER, Clara Iglesias. Por que, quando e como regular as novas tecnologias? Os desafios trazidos pelas inovações disruptivas. Revista de Direito Administrativo v. 273, 2016.

BELMIRO, N. J., Blockchain e o Potencial de Novos Modelos de Negócios: Um Mapeamento Sistemático. Disponível em:

https://search.proquest.com/openview/3e86da5605e6dbdce8bc84dad8fd8ecb/.

BENNETT MOSES, Lyria. How to think about law, regulation and technology: problems with 'technology' as a regulatory target law. Innovation and Technology, 1-20, 2013.

BINENBOJM, Gustavo. Poder de polícia, ordenação e regulação: transformações políticojurídicas, econômicas e institucionais do Direito Administrativo Ordenador. Belo Horizonte: Fórum, 2017.

BUTERIN, Vitalik, A next generation smart contract \& decentralized application platform. Disponível em: https://cryptorating.eu/whitepapers/Ethereum/Ethereum_white_paper.pdf.

CHRISTENSEN, C. M.; RAYNOR, M. E. The innovator's Solution: Creating and Sustaining Successful Growth. Boston, MA: 10 Harvard Business School Press, 2003.

DI PIETRO, Maria Sylvia Zanella. Transformações do Direito Administrativo. Revista de Direito da Administração Pública, ISSN 2595-5667, a. 1, v. 1, n. 2, jun/dez 2016.

FENWICK, Mark D.; KAAL, Wulf A.; VERMEULEN, Erik P.M.. Regulation Tomorrow: What Happens When Technology Is Faster than the Law? American University Business Law Review. Vol. 6, No. 3, article 1, 2017.

GARGARELLA, Roberto. Latin American Constitutionalism, 1810-2010: the engine room of the constitution. Oxford: Oxford University Press, 2013. pp. 172-195.

GOMES, V. J. F.; UCHOA, F. B. B.; SANTOS, T. F. S. Mapeamento Tecnológico das Patentes Desenvolvidas a partir da Tecnologia Blockchain: um cenário global. Disponível em:

https://portalseer.ufba.br/index.php/nit/article/view/27193/MAPEAMENTO\%20TECNOL\% C3\%93GICO\%20DAS\%20PATENTES\% 20DESENVOLVIDAS\%20A\%20PARTIR\%20DA \%20TECNOLOGIA\%20BLOCKCHAIN\%3A\%20UM\%20CEN\%C3\%81RIO\%20GLOBAL.

GREVE, Fabíola; SAMPAIO, Leobino; ABIJAUDE, Jauberth; et al, Blockchain e a Revolução do Consenso Sob Demanda. Disponível em:

http://143.54.25.88/index.php/sbrcminicursos/article/view/1770/1743.

GUERRA, Sérgio. Regulação estatal e novas tecnologias. Interesse Público - IP, Belo Horizonte, ano 18, n. 100, nov./dez. 2016.

GUNTER, Barrie. The effects of video games on Children: The myth unmasked. Inglaterra: Sheffield Acaemic Press, 1998. 
LUCENA, A. U., Estudo de arquiteturas dos blockchains de Bitcoin e Ethereum. Disponível em:https://www.fee.unicamp.br/sites/default/files/departamentos/dca/eadca/eadcaix/artigos/lu cena_henriques.pdf.

MACEDO, R. T., Pataca: um sistema de promoção da descentralização da moeda através de moedas criptográficas. 2014. Trabalho de formatura (Bacharelado) - Instituto de Matemática e Estatística, Universidade de São Paulo, São Paulo, 2014. [Orientador: Prof. Dr. Flávio Soares; Coorientador: Prof. Dr. Gilson Schwartz]. Disponível em: https://bcc.ime.usp.br/tccs/2014/rickmacedo/monografia.pdf.

MARQUES NETO, Floriano de Azevedo; FREITAS, Rafael Véras de. Uber, WhatsApp, Netflix: os novos quadrantes da publicatio e da assimetria regulatória. Revista de Direito Público da Economia - RDPE, Belo Horizonte, ano 14, n. 56, out./dez. 2016.

MEDAUAR. Odete. O direito administrativo em evolução. São Paulo: Revista dos Tribunais, 2003.

NAKAMOTO, Satoshi. Bitcoin: A Peer-to-Peer Electronic Cash System. Disponível em: https://web.eecs.umich.edu/ manosk/assets/slides/w18/bitcoin.pdf. Acesso em 20 de agosto de 2018.

OLIVEIRA, Rafael Carvalho Rezende; FIGUEIROA, Caio Cesar. Desafios das reformas institucionais a partir de novas tecnologias: uma abordagem pragmática ao Direito Público a partir do caso Uber. Revista de Direito Público da Economia - RDPE, Belo Horizonte, ano 14, n. 54, abr./jun. 2016.

PIRES, Timoteo Pimenta. (2016). Estudo da Tecnologia Blockchain e suas Aplicações para Provimento de Transparência em Transações Eletrônicas, Publicação PPGENE.TDXXA/2016, Departamento de Engenharia Elétrica, Universidade de Brasília, Brasília, DF.

RODRIGUES, E. I., Estudo sobre Bitcoin: escalabilidade da blockchain. Disponível em: http://www.elias19r.com/files/cv/tcc1-monografia_7987251.pdf?i=1.

SARMENTO, Daniel. Ordem constitucional econômica, liberdade e transporte individual de passageiros: $O$ "caso Uber". Revista Brasileira de Direito Público - RBDP, Belo Horizonte, ano 13, n. 50, jul./set. 2015.

SILVA, Marcelo de Sousa. Implantação de um governo eletrônico: e-Gov. Rio deJaneiro: Brasport, 2012.

SZABO, Nick, Formalizing and Securing Relationships on Public Networks, Disponível em: https://journals.uic.edu/ojs/index.php/fm/article/view/548/469

TRUBNIKOV, Dmitrii. Analysing the Impact of Regulation on Disruptive Innovations: The Case of Wireless Technology. Journal of Industry Competition and Trade, December 2017, Vol. 17, Issue 4, p.:399-420. DOI 10.1007/s10842-016-0243- 
WANG, Dexi; JIANG, Yu; SONG, Houbing, et al. Verification of Implementations of Cryptographic Hash Functions. Disponível em:

https://ieeexplore.ieee.org/abstract/document/7924403.

Trabalho recebido em 08 de março de 2020

Aceito em 25 de maio e 2020 